On such occasions, and, indeed, on all occasions when the Academy is in session for other than the transaction of its private business, the presence of a goodly number of its members would be desirable, and it ought not to forget that it is a National Academy, chartered by the government; therefore to a degree the creature of the people and their representatives in the highest domain of scientific investigation. They do not wish to direct or restrict its operations, but are content to see that they are controlled by a membership which includes the ablest specialists which the country produces, selected from time to time in accordance with a standard with which they have no particular quarrel. On the other hand, the Academy may well give great consideration to its obligations to such an enormous and unusually intelligent constituency, whose character and dignity, from the scientific standpoint, it is delegated to represent.

The November meeting will be this year in Boston, beginning on Tuesday, the sixteenth of that month.

\section{AN ESSAY ON THE CLASSIFICATION OF INSECTS.}

OF late years the phylogeny of insects has attracted considerable attention from students, and much light has been thrown upon the subject by the researches made. One of the most notable facts has been the breaking away from the old Linnæan orders and the substitution of a number of more compact assemblages for some of the almost indefinable aggregations found in the old classification. New characters have been sought, not only in structures visible externally, but even in internal anatomical peculiarities. The subject is a very interesting one, which the teacher is of necessity compelled to study more or less, and which I was led to examine more particularly when the question recently came up as to the adop- tion of some system in a general work on 'Economic Entomology', which has since been published. The conclusions reached by myself, while in general they agree with the latest published results, have been arrived at by a somewhat different method, and my ideas concerning the development of the orders are somewhat unlike those heretofore accepted. I have tried to adhere logically to a scheme of easy development, and have made use of some characters not heretofore particularly noted. Leaving aside for the present all questions as to the origin of the class 'Insecta' and as to its ancestors, I start from a developed hexapod-an archetypal Thysanuran with six, jointed legs; without wings ; with or without abdominal appendages other than functional legs; with no eyes or with ocelli only; with a head not greatly differing in size or form from the body segments; with the thoracic segments equally developed and not greatly differing except in appendages from those of the abdomen. This creature lived in moist places, perhaps partially in the water, and had the tracheal system feebly or not at all developed; absorbing oxygen chiefly through the skin and tending, perhaps, as much in the direction of an aquatic as a terrestrial life. It had no distinct metamorphosis, was oviparous, bisexed, changing little in appearance from the time it emerged from the egg until it was adult and capable of reproduction. The mouth structures were generalized, feebly developed; but with at least three, and possibly four, pairs of composite structures corresponding to mandibles, maxillæ and labium of our existing insects. The possible fourth pair may have been an endo-labium and, perhaps, the labrum with its attached epipharynx may have required a fifth pair of structures. Most essential of all was an inherent power of variation and adaptation, and probably, as with some of our present Thysanurans, reproduction was 
rapid and enormous numbers existed. The first important differentiation occurred in the mouth structure long before wings became developed, tending on the one hand to a perfection of all or most of the parts, or to a mandibulate type; on the other to a loss of certain of the structures, accompanied by a different development of the others, forming a haustellate type. In this latter branch the mandibles were never developed, the maxillary structures became elongated, separated into their parallel parts, and the labium became obsolete as a functional organ. Just how many intervening orders existed between Thysanura emandibulata and the best development of the haustellate structures it is impossible to say; but the only one in existence at the present time is Thysanoptera, also called Physopoda, otherwise Thrips.

This order I consider a distinct one on the same branch from which arose the Hemiptera, but forming merely a short spur and retaining characters which were soon lost in the main and more vigorous branch. It is a survival which has lost the power of further development, and can do no more than merely maintain itself. The main branch formed the Hemiptera, or, as I prefer to call them, the Rhyngota, of to-day; the mandibulate parts being completely lost, the labium losing all external appendages, and the maxillæ forming the jointed beak with its inclosed lancets.

The Thysanoptera and Rhyngota of all the existing orders are the only ones that do not have functional mandibles in some stage of their development. They are haustellate from their birth, and the character of the mouth parts never changes. In all the other orders, either larvæ or adults, or both, are mandibulate. I am aware that there are seeming exceptions in several orders, notably the Diptera; but it will hardly be disputed that this order is of a mandibulate stock, and many larvæ have the parts well developed.
It results from the views just stated that the Thysanoptera and Rhyngota are a division equal in value to all the other, or mandibulate, orders combined. They have their origin from the common stock; but were always haustellate or emandibulate in all stages, forming the first and lower of my main divisions. With the development of this branch, after its distinctive feature became established, I have nothing to do at present. It seemed adapted for variation in' special lines only, and, as the method of feeding was practically fixed from the beginning, there is a remarkable similarity in mouth parts throughout.

The mandibulata possessed much greater powers of variation and a mouth structure in which all the parts were developed and capable of modification, containing possibilities of much greater range in obtaining food. They lived, therefore, under all sorts of conditions, in all sorts of media, and all kinds of modification were produced; some of them short-lived, adapted only to surroundings then existing; others with greater possibilities, that exist to the present time.

The first mandibulate insect had the thoracic segments similarly developed, all of about the same size and each of them free; but the advent of wings gave opportunity for radical divisions. I have no desire to go into details here more than necessary to explain my views of classification, hence will not pretend to account for the origin or development of wings. They did appear, however, and independently at sev. eral different points. In all cases the wings were net-veined or neuropterous in type, a peculiarity which is explicable if the venation be considered of a tracheal origin. With the appearance of wings many divergences in habit were made possible and new types began to appear. Three main lines branched almost simultaneously from the common stock, each of them fairly well marked from the beginning, retaining its 
peculiarities and even intensifying them in all future subdivisions to the present time. , In the first of these the prothorax, bearing no wings, became separated from the other rings and movable, or in a sense dominant. In both the others it tended to a reduction in size or to become agglutinated with or united to the others. In a general way it may be said that the series in which the prothorax is free is lower in the scale of development, as retaining a more primitive type. The orders belonging to this subdivision or branch are the Dermoptera, Coleoptera, Plecoptera, Platyptera and Orthoptera.

If we examine this series as a whole several characters will be found to challenge attention : First, a series of similarities in the mouth structure. Omitting the Coleoptera and Platyptera, which are most highly specialized, all the others agree in the general structure of the labium. In the Earwigs, Stone-flies and Roaches a divided ligula is quite usual, and throughout the Orthoptera glossa and paraglossa are usually separate and even jointed. In the maxilla of all the orders the lacinia may be said to dominate and the galea tends to become rather a subordinate, often palpiform structure. There are numerous exceptions to this in the Coleoptera to answer special requirements, but I believe that, as a whole, my statement is correct. The maxilla tends to the exercise of mandibular functions, and the lacinia is the sclerite armed and modified for the chief labor. Throughout this entire series of orders the head is fairly well set into the prothorax. There is no development of a distinct neck between the head and the first thoracic segment, and in many cases the head can be almost entirely withdrawn into the prothorax. This is an important feature which, so far as I am aware, has not been sufficiently valued. In wingstructure the secondaries dominate throughout, and the uniform tendency is to a re- duction in size and loss of function in the primaries. Furthermore, the wings lie flat upon the back, and the secondaries are folded under the primaries. To this structure of the wings, and the method of carrying and folding them, I attribute much weight, for it seems to me that, combined with the other characters of head and thorax, it argues a community or origin and a separation from those forms differing in these features.

Among the most primitive in this series are the Orthoptera, of which the roaches and walking sticks are the most generalized in mouth structure as well as in the way the wings are carried. In this order the dominance of the secondaries as organs of flight is established, and the tegmina or primaries are more and more changed in character. The hind wings are always folded longitudinally under the primaries and sometimes both pairs are lost. In the primaries a gradual change in position occurs, part of the wing being first bent down in the crickets to protect the sides, the character becoming more prominent in the Locustidæ and most obvious in the Acrididæ which, in my opinion, are the highest of the order in point of development. Some of the roaches have the wings folded transversely as well as longitudinally, and this is a very primitive character which emphasizes the relation of these insects to the Coleoptera and points to a common ancestor.

A prominent feature in the Dermoptera and Coleoptera is that the secondaries are transversely folded, separating these orders at once from all the others except the few roaches already mentioned. It is, of course, true that there are Coleoptera in which the secondaries are not transversely folded; but these are secondary peculiarities and exceptions to the rule. I am inclined to attribute considerable importance to this character, and to give these orders an independent derivation from a Thysanuran 
spur, very close, however, to the point from which the roaches originated. The Dermoptera cannot remain associated with the Orthoptera and present more affinities to the Coleoptera from my point of view. I do not mean to say that the Earwigs were the ancestors of the beetles; but that both were derived from the same spur in which the secondaries became transversely folded, and the Dermoptera now present some of the essential characters of the ancestral Coleopteron. The Coleoptera proved a vigorous shoot and stand far the highest of all those series with a freely movable or separate prothorax.

While the terrestrial branches were developing independently, two aquatic types, the Plecoptera and Platyptera, became developed, the larval forms living similarly under the surface of the water, but assuming a winged, aërial type before becoming capable of reproducing their kind. The Plecoptera or Stone-flies have the metamorphosis incomplete, while the Platyptera have it complete. The differences in this respect are very slight, however, and I have no hesitation in classing these forms together as comparatively small divergences from one stem. It will be noted that I use the term Platyptera in a different sense from any in which it has been heretofore employed, and do not include with it either the Chrysopida, Hemerobiidae or Myrmeleonidae. Raphidia and Mantispa, which seemed at first sight referable to this series on account of the elongate prothorax, do not really belong here, because this segment is not free, but is closely united at its base with the mesothorax. The Plecoptera are, of course, much the most primitive and are a survival, the main line of development continuing in the direction of the Platyptera.

The second branch from the Thysanuran stem started with all the thoracic segments nearly equally developed. While the prothorax was of good size and in the lowest forms quite free, yet the tendency was from the very start to unite it at its base to the other thoracic segments. In this series it is always fairly well developed, sometimes even very long; but it is always closely joined to the meso-thorax at the base and is not movable, while the tendency is for the head to become free from it, and at all events not to be inserted into the thoracic segment. While we do not have anywhere in this series a distinct neck, yet on the other hand there is nowhere a retraction of the head into the prothorax. In this series both pairs of wings are similarly developed, both as to size and as to general character, while the secondaries, though frequently covered by the primaries, are never folded beneath them in any way. The primaries are always functional.

The lowest in this series, and almost the simplest in general structure, are the Isoptera, where all the thoracic segments are well developed and the prothorax is scarcely dominant, though larger and almost free from the others. The wings are very much alike, the secondaries only a little larger than the primaries, and both are laid flat upon the abdomen. The mouth structures are almost identical with those of the earwigs and some of the Orthoptera. I believe the members of this order are among the most primitive of all the terrestrial winged insects now existing, and among the most ancient, though remarkably specialized in certain directions at the present time. Though at first glance it would seem as if these insects should belong to the series in which the prothorax is free, yet the character of the wing structure forbids this association and makes the Isoptera a natural stem from which were derived the Mallophaga, Corrodentia and Neuroptera.

The Mallophaga are a degraded parasitic type which were not improbably developed from a wingless Isopteron, and perhaps at about the time that the wingless forms of 
the Corrodentia were also developed. The Corrodentia, and especially the winged forms, are peculiar in many respects and stand by themselves; but $I$ believe that they are derivatives from the branch upon which I have placed them. I do not consider it at all improbable that in the Corrodentia wings were independently developed, and indeed cannot well explain the peculiar venation on any other theory.

The Neuroptera are evidently derivatives from the Isoptera stock. Here we have the prothorax well developed in all cases, sometimes very long indeed, but always united at the base to the meso-thorax and never movable. The wings are similarly developed, both pairs used in flight, the primaries covering the secondaries, but neither pair folded in any way. All the forms are terrestrial, as indeed are all belonging to this branch. In all cases the larvæ are predatory and have a similar appearance, in the younger stages at any rate. I exclude the Sialidoe from this order, because of the movable prothorax and the folded secondaries, and include of our American families only the Mantispida, Chrysopidce, Hemerobiidoe, Myrmeleonidoe and Raphidiidoe. This branch is one of fragments, and all the groups belonging to it, or orders, if we choose to call them so, are of small extent. They may be considered remnants, and the branch as a whole does not seem to be increasing at the present time. It will be noted that as at present constituted it contains no aquatic species. Its point of origin, therefore, is very close to that from which the Orthoptera and Coleoptera branched.

The third series, in which the prothorax becomes much reduced in size and firmly articulated to the meso-thorax, has the body parts as a whole much more closely jointed and globular. The tendency is to bring the origin of the legs close together, and to the loss of the sternum as a distinct part or sclerite between the coxæ. The meso- thorax becomes dominant and best developed, bearing also the chief organs of flight. As a whole, subject to many exceptions, the tendency is to the development of the primaries, which are never reduced to mere wing-covers and never lose function. The tendency seems to be rather to a decrease in the size of the secondaries, as in Hymenoptera, and to their total loss, as in the Diptera. There is, however, a great deal of variation in this respect, and the most that can be justly said is that in this series the secondaries never become the only, or primary, organs of flight. Another point of very great importance is that here the head is nearly always more or less free or well separated, tending to the formation of a distinct neck; while there is never any insertion of the head into the prothorax. This fact will become very striking when the orders that are placed here are compared with those in the other section, and this difference in the articulation of the head has never been, in my opinion, sufficiently emphasized in our classification of the orders. It is closely correlated with the decrease, in size, of the prothorax.

In mouth structure the tendency is all in the direction of galear development in the maxilla, while the lacinia becomes constantly less important. In the Diptera, in which this series finds its highest development, the galea predominate over all other mouth structures. In the Hymenoptera the galea is always most highly developed, and particularly so in the bees, the most completely differentiated of all in the order. In the Lepidoptera the galea alone is developed into a functional organ, and in those netveined orders in which the mouth parts are not rudimentary merely the galea is at least as well developed as and never subordinated to the lacinia. The orders in which I placed in this series are Odonata, Ephemerida, Trichoptera, Mecoptera, Hymenoptera, Siphonoptera and Diptera. 
The Odonata presents the characters of the series in a very compact form and evidently had an early origin, though now quite decidedly specialized. As they exist at present they are the end of a very distinct line, once much more numerous than they are now, and they show us a survival of one of nature's experiments in methods of reproduction. The separation of the copulatory organs from the testes is a unique character for which some cause must have existed. I am aware that elsewhere similar separations exist, but I am not acquainted with any similar character in the Insecta. At all events the line leading to the Dragon flies was single, and none of our existing orders lead to it.

The geologic record, and their loosely jointed make-up, point to the Ephemerida as the most primitive in this series; but even here we have, well-marked in most of the forms, the free head, fairly distinct neck, unimportant prothorax, always closely joined to the meso-thorax, and the dominant primaries. The order has not varied much and is a survival; but from the same stem bearing the Ephemerida all the other orders of this branch have originated, giving them all a derivation from an aquatic larval type.

As the earliest spur from this branch we have the Trichoptera, in which the larvæ remain aquatic, but have assumed a cylindrical, caterpillar-like form, and from these the Lepidoptera were derived in comparatively recent times. The break between these two orders is not very great even at present, and in many of the Lepidoptera characters of a Trichopterous type may yet be distinguished.

The Mecoptera branched from the same stem with the Trichoptera with similar worm or caterpillar-like larvæ, some of which were probably aquatic; others lived in mud or moist ground, where some of them are still to be found, while yet others be- came entirely terrestrial. From one of the semi-aquatic forms the Diptera were derived. In the adult Mecopter $\alpha$, instead of a loss of mouth parts, which was the tendency in the Trichoptera, we had rather a development of all the parts in parallel series, much as in Panorpa, which even at present retains many of the primitive characters.

I am inclined to give the phytophagus Hymenoptera a much earlier origin than the Diptera and to derive them from the Mecopterous branch before it became very highly specialized. The Diptera seem to me to be the most recent of all the insect lines, and embody the highest type of that series in which the thoracic rings are united. Here the head is entirely distinct, the prothorax firmly united with the other rings, which are, themselves, solidly joined. The forewings dominate to the exclusion of the secondaries, and the galear structures of the mouth are the most highly specialized, showing, however, when closely studied, a remarkable resemblance to those of the Hymenoptera and pointing very strongly to a community of origin.

The Siphonoptera, or fleas, are entitled to ordinal recognition. They have much in common with the Diptera, but a type of mouth structure which could not possibly have been derived from the type now existing in that order. There is nothing, however, to prevent the belief that they developed from the same Mecopterous branch which culminated in the Diptera. In fact, the mouth parts of the fleas resemble those Mecoptera very interestingly in certain directions, and will be, I think, best understood by comparing them with that series.

I am quite aware that objections may be urged to this scheme, and that it is imperfect in some repects, but so also are all the others that have been proposed; and I believe, as I look at the matter, that my plan answers more of the objections than any other that I have seen. Nothing known 
to me contradicts it more vitally than any other that has been proposed.

I have accorded very little place to the character of the metamorphosis, because there is no hard and fast line between complete and incomplete; but the closer comparative study of early stages will unquestionably help out our future classification. I have not made use of any one character as the basis of my scheme of division, be- cause I do not think nature works in that way, and finally, I have used adult stages only, because I see in the adult ready to reproduce, the species. It is the culmination of individual growth, and until it is ready to reproduce it is incomplete, subject to change, and not an expression of the point to which its development has attained. In another form my scheme may be expressed as follows :

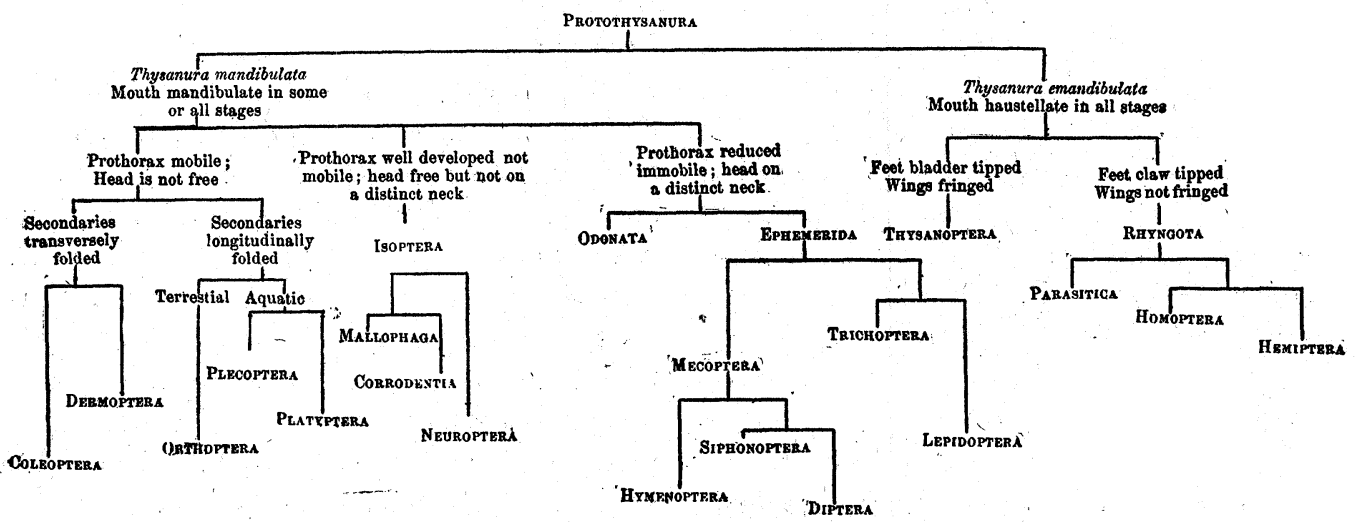

Rutgers College.

John B. Sмith.

HOW MAY MUSEUMS BEST RETARD THE ADVANCE OF SCIENCE?*

VARIous subjects have at various times suggested themselves to me as appropriate for a paper to be submitted to this Association, but when I read the magnificently exhaustive address by Dr. Brown Goode, published in our last Report, it was manifest that all the ideas I had ever had were anticipated in that masterly production. There is, however, one side of our subject which has hardly had the attention paid to it that it undoubtedly deserves. We have been taught how best to arrange our museums for the satisfaction of the collector, of the student, of the investigator, or of the British public, but no one has ever pointed out to us the magnificent opportunities that are at our disposal whereby we may accomplish the great work of retarding the ad-

\footnotetext{
* From Report of Museum Association for 1896.
}

vance of science. It will perhaps not be wholly waste of time if we devote a few minutes this morning to considering this great power that is in our hands and how we may avail ourselves of it.

There are certain lines of conduct that are so surely and obvjously prejudicial to science that the most uninstructed curator scarcely needs to be reminded of them. None of us but has been taught how to bewilder the eyes of the public with thirty specimens of an object, all placed the same way up, and displaying as few of its essential characters as possible, when one specimen properly labelled would have sufficed. We know how to strike dullness through the hearts of thousands by our funereal rows of stuffed birds with their melancholy lines of Latin names; we know how to chill the enthusiasm of the young and to disgust the susceptibilities of tender souls by the 